Research Article

\title{
Incidental thyroid cancer in patients undergoing surgery for benign multinodular goitre: A retrospective clinical study
}

\section{Adnan Özpek ${ }^{1^{*}}$ and Cumhur Selçuk Topal ${ }^{2}$}

${ }^{l}$ Department of General Surgery, Health Sciences University, Umraniye Training and Research Hospital, Istanbul, Turkey

${ }^{2}$ Department of Surgical Pathology, Health Sciences University, Umraniye Training and Research Hospital, Istanbul, Turkey

\section{ARTICLE INFO \\ Article history: \\ Received: 28 February, 2019 \\ Accepted: 12 March, 2019 \\ Published: 29 March, 2019}

\section{Keywords:}

Fine needle aspiration biopsy

thyroid carcinoma

thyroidectomy

thyroid nodule, goiter

\begin{abstract}
A B S T R A C T
Background and Objectives: In this study, we aimed to analyze the incidence and findings of incidental thyroid carcinoma (ITC) in patients undergoing thyroidectomy for benign multinodular goitre (MNG).

Methods: A total of 361 consecutive MNG patients with benign (Bethesda II) Fine Needle Aspiration Cytology (FNAC) results who underwent thyroidectomy without any suspicion of malignancy or malignancy between January 2009 and January 2018 were retrospectively analyzed. Patients with ITC were evaluated in terms of age, sex, operation indication, surgery, tumor type, tumor diameter, tumor multicentricity and complications.

Results: Of the total 361 patients, $288(79.8 \%)$ were female and $73(20.2 \%)$ were male and the mean age was 48.5 years. One-hundred-and-fourteen $(31.6 \%)$ of the cases were operated for toxic MNG, $32(8.9 \%)$ for toxic adenoma, $209(57.9 \%)$ for $4 \mathrm{~cm}$ and larger nodule, and $6(1.6 \%)$ for nodules accompanying parathyroid adenoma. ITC was detected in $42(11.6 \%)$ cases; Papillary thyroid microcarcinoma was found in $38(10.5 \%)$ and papillary thyroid carcinoma in $4(1.1 \%)$. ITC was found in equal proportion $(11.6 \%)$ in patients with and without hyperthyroidism.

Conclusions: We believe that TT or HT is a suitable surgical treatment method in order to reduce the risk of reoperation and related morbidity in benign MNG patients.
\end{abstract}

\section{Introduction}

The incidence of thyroid cancer increases rapidly and has tripled over the past 30 years, according to US data. From 1990s to 2011 the incidence of thyroid cancer increased from 4,9/100,000 to 14,7/100,000. Despite this increase, there was no significant change in thyroid cancer-related mortality incidence, and in the last 30 years it was stable in about $0.5 / 100,000$ [1]. The increase in the incidence of thyroid cancer is thought to be associated with an increase in the diagnosis of subclinical thyroid cancer. Autopsy studies support this hypothesis. In studies conducted in different countries, the prevalence of thyroid cancer from $3 \%$ to $35 \%$ was found in autopsies of people who died due to other reasons. The development of imaging methods, the increase in Fine Needle Aspiration Cytology (FNAC) numbers, the more widespread application of total thyroidectomy instead of subtotal thyroidectomy and the more detailed examination of pathological specimens affect this increase. In fact, between 1996 and 2010, the incidence of thyroid cancer in South Korea increased from 10,6/100,000 to 111,3 in females and from $1,9 / 100,000$ to 27,0 in males [1]. One study predicts that thyroid cancer will be the third most common cancer among women in 2019 in USA [2].

According to the methods of diagnosis, thyroid cancers can be grouped in three ways: clinically identifiable (non-incidental), radiologically

*Correspondence to: Dr. Adnan Özpek, Health Sciences University, Istanbul Umraniye Training and Research Hospital, Department of General Surgery, Istanbul, Turkey; Fax: Fax: +90-216-6327124; Tel: +90-5322544882; E-mail: adnanozpek@mynet.com 
determined (clinically unspecified) and pathologically determined (clinically and radiologically undetermined) cancer. The definition of Incidental Thyroid Cancer (ITC) can be performed in four different categories: 1) cancers with pre-operative benign cytopathology, which are detected in the final histopathological examination after thyroidectomy, 2) cancers found as a result of ultrasonographic and cytopathological examination, with no clinical signs of cancer, 3) cancers with clinical, ultrasonographic and cytopathologically found lymph node metastasis that primary cancer can be detected only in the thyroidectomy specimen, 4) cancers detected in the ectopic thyroid tissue and diagnosed clinically by metastasis [2-3].

In the literature, ITC rates up to the range of $40 \%$ in patients who underwent thyroidectomy due to benign multinodular goiter (MNG) and in most of the studies in the range of $7-20 \%$ are reported. Most of them were well-differentiated, in the low-risk group and papillary microcarcinomas smaller than $1 \mathrm{~cm} \mathrm{[2-11].}$

In this study, we aimed to analyze the findings of patients who had benign cytopathology in our clinic and who had ITC in the thyroid parenchyma other than the FNAC applied nodule in the definitive histopathological examination after thyroidectomy.

\section{Materials and Methods}

The study was reviewed and approved by Institutional Ethical Committee (No: 16708/60) and conducted in accordance with the principles of the Declaration of Helsinki. Written informed consent was obtained from all patients. The consecutive patients who were operated by a single endocrine surgeon in the General Surgery Clinic of our hospital between January 2009 and January 2018 were retrospectively analyzed in a prospective database. FNAC was applied to scintigraphically cold nodules in patients with hyperthyroidism, and nodules with the largest and / or sonographically suspicious nodules in ultrasound examination. The FNAC procedure of all patients was performed by the Interventional Radiologist under ultrasound guidance and was interpreted by specialized cytopathologists. Patients without preoperative FNAC and with inadequate (Bethesda I), suspected (Bethesda III, IV and V) and malignant (Bethesda VI) FNAC were excluded from the study. Patients with benign preoperative cytopathological result (Bethesda II); toxic multinodular goitre, toxic adenoma, $4 \mathrm{~cm}$. or larger nodular goitre, pressure symptoms and patients undergoing thyroidectomy for retrosternal goitre were included in the study. The patients underwent total thyroidectomy (TT) or hemithyroidectomy (HT). The patients diagnosed with incidental carcinoma in the thyroid parenchyma other than FNAC applied nodule were evaluated in terms of age, gender, operation indication, surgery, tumor type, tumor size, tumor multicentricity and complications.

\section{Statistical analysis}

Analysis of the results was performed using the IBM SPSS Statistics 22 (IBM, SPSS, USA). The suitability of the study parameters to normal distribution was evaluated by Shapiro Wilks test. Student-t test was used to compare descriptive statistical methods (mean, standard deviation, frequency) and quantitative data of normal distribution. Chi-square test and Continuity (Yates) correction were used to compare qualitative data. Significance was defined as $\mathrm{p}<0.05$.

\section{Results}

A total of 361 patients with benign FNAC results (Bethesda II) from 730 consecutive patients who underwent thyroidectomy in our clinic between January 2009 and January 2018 were included in the study. Of the patients; 288 (79.8\%) were female , $73(20.2 \%)$ were male and the mean age was $48.57 \pm 12.38$ years (range: 18-78). One-hundred-andfourteen $(31.6 \%)$ of the cases were operated for toxic MNG, $32(8.9 \%)$ for toxic adenoma, $209(57.9 \%)$ for $4 \mathrm{~cm}$ and larger nodule, and $6(1.6 \%)$ for nodules accompanying parathyroid adenoma. In addition, 53 (14.7\%) of these patients had retrosternal goitre and pressure symptoms.TT was applied to $272(75.3 \%)$ patients and HT was applied to 89 (24.7\%) patients (Table 1).

Table 1: Features of all patients

\begin{tabular}{|l|l|}
\hline Gender & $\begin{array}{l}\text { Female: } \mathrm{n}=288(79.8 \%) \\
\text { Male: } \mathrm{n}=73(20.2 \%)\end{array}$ \\
\hline Age & $\begin{array}{l}\text { Mean } \pm \text { SD: } 48.57 \pm 12.38 \\
\text { Min-Max.: } 18-78\end{array}$ \\
\hline Surgery procedure & $\begin{array}{l}\text { HT: } \mathrm{n}=89(24.7 \%) \\
\text { TT: } \mathrm{n}=272(75.3 \%)\end{array}$ \\
\hline Indication of surgery & $\begin{array}{l}\text { Toxic adenoma: } \mathrm{n}=32(8.9 \%) \\
\text { Toxic MNG: } \mathrm{n}=114(31.6 \%) \\
4 \text { cm or larger nodules: } \mathrm{n}=209(57.9 \%) \\
\text { Parathyroid adenoma with thyroid } \\
\text { nodule: } \mathrm{n}=6(1.6 \%)\end{array}$ \\
\hline Incidental Ca & $\begin{array}{l}\text { Yes: } \mathrm{n}=42(11.6 \%) \\
\text { No: } \mathrm{n}=319(88.4 \%)\end{array}$ \\
\hline
\end{tabular}

When all patients were evaluated according to age; the mean age of males was statistically higher than females $(p=0.002)$, the mean age of patients with hyperthyroidism was found to be significantly higher than those without hyperthyroidism $(\mathrm{p}=0.005)$ and the mean age of the patients with incidental $\mathrm{Ca}$ was significantly higher than those without incidental $\mathrm{Ca}(\mathrm{p}=0.004)$ (Table 2). ITC was found in $42(11.6 \%)$ patients in the postoperative definitive histopathological examination. Thirty-three $(9.1 \%)$ of the patients with incidental carcinoma were female, $9(2.5 \%)$ were male and the mean age was 53.4 (range: 25-78). Thirteen patients $(3.6 \%)$ were operated for toxic MNG, 4 (1.1\%) toxic adenoma and $25(6.9 \%)$ for a $4 \mathrm{~cm}$ and larger nodule. TT was applied to 32 patients $(8.8 \%)$ and $\mathrm{HT}$ to $10(2.8 \%)$ patients. Histopathological examination showed that $38(10.5 \%)$ patients had papillary thyroid microcarcinoma (PTMC) smaller than $1 \mathrm{~cm}$ in diameter and $4(1.1 \%)$ had $1 \mathrm{~cm}$ or greater papillary thyroid carcinoma (PTC). In 18 patients (5\%) single, $24(6.6 \%)$ multiple, totally 72 tumor loci were found. Tumor focus was found to be $1-5 \mathrm{~mm}$ in $22(6.1 \%)$ patients, $6-9 \mathrm{~mm}$ in 16 (4.4\%) patients and $1 \mathrm{~cm}$ or larger in 4 patients (1.1\%).Twenty-five $(11.6 \%)$ of the patients without hyperthyroidism and $17(11.6 \%)$ of the patients who were operated for hyperthyroidism had incidental carcinoma at the same rate (Table 3).

Three patients who underwent lobectomy and who had an incidental PTC of more than $1 \mathrm{~cm}$ were re-operated and the complementary 
thyroidectomy was performed to the counter thyroid lobe. Complementary thyroidectomy was not performed in patients who had lobectomy and incidental PTMC. When the patients with incidental Ca were evaluated in terms of gender and hyperthyroidism; there was no statistically significant difference in terms of sex distribution rates $(p=0,538)$ and in the incidence of hyperthyroidism $(p=1)$ between patients with and without incidental $\mathrm{Ca}$ (Table 4). When the postoperative complications of all patients were examined; 24 (6.6\%) of patients had transient hypocalcemia, $1(0.3 \%)$ permanent hypocalcemia, $21(5.8 \%)$ unilateral transient vocal cord paralysis, $1(0.3 \%)$ unilateral permanent vocal cord paralysis, $15(4.1 \%)$ seroma, $1(0.3 \%)$ hemorrhage and $4(1.1 \%)$ had wound infection (Table 5).

Table 2: Evaluation of age according to gender, hyperthyroidism and incidental carcinoma presence

\begin{tabular}{lll}
\hline & & Age \\
\cline { 3 - 3 } Gender & Male & Mean \pm SD \\
\hline \hline & Female & $52,55 \pm 11,47$ \\
\cline { 2 - 3 } & $\mathbf{p}$ & $\mathbf{0 , 0 0 2} *$ \\
\hline Hyperthyroidism & Without & $47,09 \pm 11,61$ \\
& With & $50,79 \pm 13,18$ \\
\cline { 2 - 3 } & $\mathbf{p}$ & $\mathbf{0 , 0 0 5} *$ \\
\hline Incidental Ca & Without & $47,90 \pm 12,43$ \\
& With & $53,67 \pm 10,83$ \\
\cline { 2 - 3 } & $\mathbf{p}$ & $\mathbf{0 , 0 0 4} *$ \\
\hline
\end{tabular}

Student t test $* p<0.05$

Table 3: Features of incidental carcinoma patients

\begin{tabular}{|l|l|}
\hline Total incidental carcinoma & $\mathrm{n}=42(11.6 \%)$ \\
\hline Gender & $\begin{array}{l}\text { Female: } \mathrm{n}=33(9,1 \%) \\
\text { Male: } \mathrm{n}=9(2.5 \%)\end{array}$ \\
\hline Operation & $\begin{array}{l}\text { HT: } \mathrm{n}=10(2.8 \%) \\
\text { TT: } \mathrm{n}=32(8.8 \%)\end{array}$ \\
\hline Tumor type & $\begin{array}{l}\text { Papillary carcinoma: } \mathrm{n}=4(1.1 \%) \\
\text { Papillary Microcarcinoma: } \mathrm{n}=38 \\
(10.5 \%)\end{array}$ \\
\hline Tumor size & $\begin{array}{l}1-5 \text { mm: } \mathrm{n}=22(6.1 \%) \\
6-9 \text { mm: } \mathrm{n}=16(4.4 \%) \\
\geq 10 \text { mm: } \mathrm{n}=4(1.1 \%)\end{array}$ \\
\hline Number of focus & $\begin{array}{l}\text { Single focus: } \mathrm{n}=18(5 \%) \\
\text { Multiple focus: } \mathrm{n}=24(6.6 \%)\end{array}$ \\
\hline Indication of surgery & $\begin{array}{l}\text { Toxic MNG: } \mathrm{n}=13(3.6 \%) \\
\text { Toxic adenoma: } \mathrm{n}=4(1.1 \%) \\
4 \text { cm and larger nodule: } \mathrm{n}=25 \\
(6.9 \%)\end{array}$ \\
\hline Hyperthyroidism & $\begin{array}{l}\text { Yes: } \mathrm{n}=17 / 146(11.6 \%) \\
\text { No }: \mathrm{n}=25 / 215(11.6 \%)\end{array}$ \\
\hline
\end{tabular}

Table 4: Evaluation of hyperthyroidism and gender parameters according to the presence of incidental carcinoma

\begin{tabular}{|c|c|c|c|c|}
\hline & & \multicolumn{2}{|c|}{ Incidental Ca } & \multirow{3}{*}{$\mathbf{p}$} \\
\hline & & Without & With & \\
\hline & & n $(\%)$ & n $(\%)$ & \\
\hline \multirow[t]{2}{*}{ Gender } & Male & $\begin{array}{l}63 \\
(19,7 \%)\end{array}$ & $10(23,8 \%)$ & \multirow[t]{2}{*}{$\begin{array}{l}10,53 \\
8\end{array}$} \\
\hline & Female & $\begin{array}{l}256 \\
(80,3 \%)\end{array}$ & $32(76,2 \%)$ & \\
\hline \multirow[t]{2}{*}{ Hyperthyroidism } & Without & $\begin{array}{l}190 \\
(59,6 \%)\end{array}$ & $25(59,5 \%)$ & \multirow[t]{2}{*}{$\begin{array}{l}{ }^{2} 1,00 \\
0\end{array}$} \\
\hline & With & $\begin{array}{l}129 \\
(40,4 \%)\end{array}$ & $17(40,5 \%)$ & \\
\hline
\end{tabular}

Table 5: Postoperative complications

\begin{tabular}{|l|l|}
\hline Hypocalcemia & $\begin{array}{l}\mathrm{n}=24(6.6 \%) \text { Transient } \\
\mathrm{n}=1(0.3 \%) \text { Permanent } \\
\text { Vocal cord paralysis (unilateral) }\end{array}$ \\
$\begin{array}{l}\mathrm{n}=21(5.8 \%) \text { Transient } \\
\mathrm{n}=1(0.3 \%) \text { Permanent }\end{array}$ \\
\hline Seroma & $\mathrm{n}=15(4.1 \%)$ \\
\hline Hemorrhage & $\mathrm{n}=1(0.3 \%)$ \\
\hline Wound infection & $\mathrm{n}=4(1.1 \%)$ \\
\hline
\end{tabular}

\section{Discussion}

Although there are studies reporting that the incidence of differentiated thyroid cancer has increased by 3-15 times in the last three decades, the same studies report that the mortality rates due to thyroid cancer remain constant. The reason for this is thought to be changes in diagnosis, imaging, surgical treatment approach and histopathological examination methods [1]. ITC can be defined as malignancy in histopathological examination of patients who underwent thyroidectomy except for malignant and suspicious FNAC [2]. In the literature, there are clinical studies reporting the histopathologically diagnosed ITC ratio between $2.2 \%$ and $40 \%$ [2-11]. Similar rates are determined in autopsy studies of people who died for other reasons. A meta-analysis of 35 studies and 12,834 autopsies between 1949 and 2007 found ITC up to $11.2 \%$. The interesting finding in this study is that there is no significant increase in prevalence in autopsy studies since the 1940s. This finding strongly supports the link between development of diagnostic methods and increase in the incidence of ITC in the present day [12]. In the diagnosis and follow-up of thyroid nodules clinically and radiologically as recommended in the American Thyroid Association (ATA) guidelines; Ultrasound guided FNAC because of its low cost and easy and simple method and Bethesda Scoring System for interpretation is widely preferred all over the world [13-15]. When the studies in the literature are examined, hyperthyroidism and benign MNG are the most common indications for patients operated with benign causes. Ladra González et al.'s study of 1415 patients in 2016 showed; $17.9 \%$ of the cases with incidental carcinoma were operated for MNG and $12.4 \%$ for hyperthyroidism [16]. 
In our study, 25 (6.9\%) of the patients with ITC were operated for MNG and 17 (4.7\%) for hyperthyroidism. In the literature, in some sources, it has been reported that incidental carcinoma detection rates are higher in patients with hyperthyroidism compared to non-toxic benign MNG. In another study, there was no statistically significant difference in incidental carcinoma in patients operated for non-toxic benign MNG and hyperthyroidism [16-17]. However, more aggressive variant papillary carcinoma was detected in hyperthyroid patients [16-18]. In our study, incidental carcinoma was found in the same proportion (11.6\%) in patients with non-toxic benign MNG and hyperthyroidism.The World Health Organization (WHO) recommends the term microcarcinoma for tumors smaller than $10 \mathrm{~mm}$. In the publications, it was determined that the most common histopathological type of incidental carcinoma was papillary carcinoma and the majority of them were well-differentiated papillary microcarcinoma [2-11, 16, 17]. Similarly, in our study, all cases were histologic type of papillary carcinoma and most of them were PTMC.

In the literature, TT is considered to be the most appropriate surgical procedure for patients with well-differentiated thyroid carcinoma. TT is also recommended in patients with hyperthyroidism with severe ophthalmopathy, radiation history in the head and neck region, large thyroid gland, suspected FNAC and in goitre with pressure symptoms [19-22]. Similarly, there are many studies suggesting a TT or Dunhill's procedure (hemithyroidectomy with counter lateral near-total resection) to eliminate the possibility of reoperation due to recurrence and incidental cancer diagnosis for benign MNG [23-28].

The most common and most important complications of thyroidectomy are recurrent laryngeal nerve palsy, hypocalcemia and hematoma. A meta-analysis and systematic review of 14 studies and 10,478 patients published in 2017; 0-4\% of transient recurrent laryngeal nerve paralysis, $0-2 \%$ recurrent laryngeal nerve paralysis, $1-21 \%$ transient hypocalcemia, $0-2 \%$ hematoma and 0-26\% total complication rates have been reported [29]. In our study, all complications were examined; $24(6.6 \%)$ of patients had transient hypocalcemia, $1(0.3 \%)$ permanent hypocalcemia, $21(5.8 \%)$ unilateral transient vocal cord paralysis, $1(0.3 \%)$ unilateral permanent vocal cord paralysis, $15(4.1 \%)$ seroma, $1(0.3 \%)$ hemorrhage and $4(1.1 \%)$ had wound infection and were similar to the literature. In many studies in the literature, more complication rates have been reported in relapses and re-operations due to cancer diagnosis [29-31]. Especially when compared with primary TT; the rate of complications up to 5-10 times for permanent recurrent nerve paralysis and persistent hypoparathyroidism is quite striking [32-34]. On the other hand, no significant difference was reported between the patients who underwent TT for the first operation due to benign MNG and those who underwent subtotal thyroidectomy [35-36].

\section{Conclusions}

Based on the results of our study and the findings in the literature; If TT is performed in an experienced center and by an experienced surgeon in this field, we can say that this procedure is safe with minimal complications. The aim of surgical treatment in MNG is to eliminate the disease with low surgical complication rates and to minimize the risk of re-operation. In other words, the advantage of TT performed in the first operation in benign MNG patients is that it eliminates the possibility of re-operation with a greater risk of complications and prevents relapse. In the postoperative definitive histopathological examination, we detected incidental papillary carcinoma in $11.6 \%$ of patients who underwent surgery due to MNG and preoperative benign FNAC result. Therefore, we think that TT or HT is a suitable surgical method in patients who required thyroidectomy due to benign MNG.

\section{Disclosure of conflict of interest}

None

\section{Funding}

None

\section{REFERENCES}

1. Davies L, Morris LG, Haymart M, Chen AY, Goldenberg D, et al (2015) American Association of Clinical Endocrinologists and American College of Endocrinology Disease State clinical review: The increasing incidence of thyroid cancer. Endocr Pract 21: 686-696. [Crossref]

2. Fama F, Sindoni A, Cicciu M, Polito F, Piquard A, et al. (2018) Preoperatively undiagdosed papillary thyroid carcinoma in patients thyroidectomized for benign multinodular goitre. Arch Endocrinolg Metab 62: 139-148. [Crossref]

3. J Boucek, J Kastner, J Skrivan, E Grosso, B Gibelli, et al. (2009) Occult thyroid carcinoma. Acta Otorhinolaryngol Ital 29: 296-304. [Crossref]

4. Karalus M, Tamatea JA, Conaglen HM, Meyer-Rochow, Conaglen JV, et al. (2018) Rates of unsuspected thyroid cancer in multinoduler thyroid disease. NZ Med J 131: 69-74. [Crossref]

5. Slijepcevic N, Zivaljevic V, Marinkovic J, Sipetic S, Aleksandar Diklic, et al. (2015) Retrospective evaluation of the incidental finding of 403 papillary thyroid microcarcinomas in 2466 patients undergoing throid surgery for presumed benign thyroid disease. BMC Cancer 15 : 330. [Crossref]

6. Bahl M, Sosa JA, Nelson RC, Esclamado RM, Choudhury KR, et al. (2014) Trends in incidentally identified thyroid cancers over a decade: a retrospective analysis of 2,090 surgical patients. World J Surg 38: 1312-1317. [Crossref]

7. Costamagna D, Pagano L, Caputo M, Leutner M, Mercalli F, et al. (2013) Incidental cancer in patients surgically treated for benign thyroid disease. Our experience at a single institution. G Chir 34: 2126. [Crossref]

8. Smith JJ, Chen X, Schneider DF, Broome JT, Sippel RS, et al. (2013) Cancer after thyroidectomy: a multi-institutional experience with 1,523 patients. J Am Coll Surg 216: 571-577. [Crossref]

9. Negro R, Piana S, Ferrari M, Ragazzi M, Gardini G, et al. (2013) Assessing the risk of false-negative finr-needle aspiration cytology and of incidental cancer in noduler goitre. Endocr Pract 19: 444-450. [Crossref]

10. Christakis I, Dimas S, Kafetzis ID, Roukounakis N (2018) Risk stratification of 282 differentiated thyroid cancers found incidentally in 1369 total thyroidectomies according to the ATA guidelines; implications for management and treatment. Ann R Coll Surg Engl 100: 357-365. [Crossref] 
11. Maturo A, Tromba L, De Anna L, Carbotta G, Livadoti G, et al. (2017) Incidental thyroid carcinomas. A retrospective study. G Chir 38: $94-$ 101. [Crossref]

12. Furuya Kanamori L, Bell KJ, Clark J, Glasziou P, Doi SAR (2016) Prevalence of Differentiated Thyroid Cancer in Autopsy Studies Over Six Decades: A Meta-Analysis. J Clin Oncol 34: 3672-3679. [Crossref]

13. Hammad AY, NoureldineSI, Hu T, Ibrahim Y, Masoodi HM, et al. (2016) A meta-analysis examining the independent association between thyroid nodule size and malignancy. Gland Surg 5: 312-317. [Crossref]

14. Bozbıyık O, Öztürk Ş, Ünver M, Erol V, Bayol Ü, et al. (2017) Reliab fine needle aspiration biopsy in large thyroid nodules. Turk J Surg 33: 10-13. [Crossref]

15. 15.Cibas ES, Ali SZ (2017) The 2017 Bethesda System for Reporting Thyroid Cytopathology. Thyroid 27: 1341-1346. [Crossref]

16. Ladra González MJ, Peteiro González D, Aliyev E, Barreiro Morandeira F, Cameselle Teijeiro JM (2017) Comments on «Incidental versus non-incidental thyroid carcinoma: Clinical presentation, surgical management and prognosis. Endocrinol Diabetes Nutr 64: 232-233. [Crossref]

17. Mehanna H, Al Maqbili T, Carter B, Martin E, Campain N, et al. (2014) Differences in the recurrence and mortality outcomes rates of incidental and nonincidental papillary thyroid microcarcinoma: a systematic review and meta-analysis of 21,329 person-years of follow-up. J Clin Endocrinol Metab 99: 2834-2843. [Crossref]

18. Preece J, Grodski S, Yeung M, Bailey M, Serpell J (2014) Thyrotoxicosis does not protect against incidental papillary thyroid cancer. Surgery 156: 1153-1156. [Crossref]

19. Liu ZW, Masterson L, Fish B, Jani P, Chatterjee K (2015) Thyroid surgery for Graves' disease and Graves' ophthalmopathy. Cochrane Database Syst Rev 25: CD010576. [Crossref]

20. Tezelman S, Borucu I, Senyurek Giles Y, Tunca F, Terzioglu T (2009) The change in surgical practice from subtotal to near-total or total thyroidectomy in the treatment of patients with benign multinodular goitre. World J Surg 33: 400-405. [Crossref]

21. Giles Y, Boztepe H, Terzioglu T, Tezelman S (2004) The advantage of total thyroidectomy to avoid reoperation for incidental thyroid cancer in multinodular goitre. Arch Surg 139: 179-182. [Crossref]

22. Liu Q, Djuricin G, Prinz RA (1998) Total thyroidectomy for benign thyroid disease. Surgery 123: 2-7. [Crossref]
23. Delbridge L, Guinea AI, Reeve TS (1999) Total thyroidectomy for bilateral benign multinodular goitre: effect of changing practice. Arch Surg 134: 1389-1393. [Crossref]

24. Mishra A, Agarwal A, Agarwal G, Mishra SK (2001) Total thyroidectomy in benign thyroid disorders in an endemic region. World J Surg 25: 307-310. [Crossref]

25. Wheeler MH (1998) Total thyroidectomy for benign thyroid disease. Lancet 351: 1526-1527.

26. Gough IR, Wilkinson D (2000) Total thyroidectomy for management of thyroid disease. World J Surg 24: 962-965. [Crossref]

27. Mauriello C, Marte G, Canfora A, Napolitano S, Pezzolla A, et al. (2016) Bilateral benign multinoduler goitre: What is the adequate surgical therapy? A review of literature. Int J Surg 28: 7-12. [Crossref]

28. Kaliszewski K, Strutynska-Karpinska M, Zubkiewicz-Kucharska A, Wojtczak B, Paweł Domosławski, et al. (2016) Should the prevalance of incidental thyroid cancer determine the extent of surgery in multinoduler goitre? PloS One 11: e0168654. [Crossref]

29. Khadra H, Mohamed S, Hauch A, Carter J, Hu T, et al. (2017) Safety of same- day thyroidectomy: meta-analysis and systematic review. Gland Surg 6: 292-301. [Crossref]

30. Bellantone R, Lombardi CP, Bossola M, Boscherini M, De Crea C, et al. (2002) Total thyroidectomy for management of benign thyroid disease: review of 526 cases. World J Surg 26: 1468-1471. [Crossref]

31. Bron LP, O'Brien CJ (2004) Total thyroidectomy for clinically benign disease of the thyroid gland. Br J Surg 91: 569-574. [Crossref]

32. Benkhadoura M, Taktuk S, Alobedi R (2017) Recurrent laryngeal nevre injury and hypoparathyroidism rates in reoperative thyroid surgery. Turk J Surg 33: 14-17. [Crossref]

33. Kaliszewski K, Wojtczak B, Grzegrzolka J, Bronowicki J, Saeid S, et al. (2018) Nontoxic multinodular goitre and incidental thyroid cancer: What is the best surgical strategy? A retrospective study of 2032 patients. Int J Endocrinol 2018: 4735436. [Crossref]

34. Cappelani A, Zanghi A, Cardi F, Cavallaro A, Piccolo G, et al. (2017) Total Thyroidectomy: the first, the best. The recurrent goitre issue. Clin Ter 168: 194-198. [Crossref]

35. Gangappa RB, Kenchannavar MB, Chowdary PB, Patanki AM, Ishwar M (2016) Total thyroidectomy for benign thyroid diseases: What is the price to be paid? J Clin Diagn Res 10: 4-7. [Crossref]

36. Koyuncu A, Dökmetas HS, Turan M, Aydin C, Karadayi K, et al. (2003) Comparison of different thyroidectomy techniques for benign thyroid disease. Endocr J 50: 723-737. [Crossref] 